\title{
The Effects of Interest Rates on Mortgage Prepayments
}

\section{Citation}

Green, Jerry, and John B. Shoven. 1986. The effects of interest rates on mortgage prepayments. Journal of Money, Credit and Banking 18, no. 1: 41-59.

\section{Published Version}

http://dx.doi.org/10.2307/1992319

\section{Permanent link}

http://nrs.harvard.edu/urn-3:HUL.InstRepos:3204664

\section{Terms of Use}

This article was downloaded from Harvard University's DASH repository, and is made available under the terms and conditions applicable to Other Posted Material, as set forth at http:// nrs.harvard.edu/urn-3:HUL.InstRepos:dash.current.terms-of-use\#LAA

\section{Share Your Story}

The Harvard community has made this article openly available.

Please share how this access benefits you. Submit a story.

Accessibility 
NBER WORKING PAPER SERIES

THE EFFECTS OF INTEREST RATES ON MORTGAGE PREPAYMENTS

Jerry Green

John B. Shoven

Working Paper No. 1246

\section{NATIONAL BUREAU OF ECONOMIC RESEARCH \\ 1050 Massachusetts Avenue \\ Cambridge, MA 02138 \\ December 1983}

This paper was supported by the Federal Home Loan Bank of San Francisco. We would like to thank Cindy Fraleigh for her research assistance. Adrei Schleifer and Tom Mroz also provided us with their help. The suggestions of J. H. Humphrey, C. A. Baird, and A. $R$. Hall are gratefully acknowledged. The research reported here is part of the NBER's research program in Taxation. Any opinions expressed are those of the authors and not those of the National Bureau of Economic Research, Federal Home Loan Bank, Harvard or Standford University. 
NBER Working Paper. \#1246

December 1983

The Effects of Interest Rates on

Mortgage Prepayments

\section{ABSTRACT}

Three main types of mortgages are fixed interest contracts which automatically fall due on the sale of a dwelling, fixed rate loans which are assumable by a buyer, and floating rate instruments. When interest rates rise, the fall in the economic value of these assets in savings and loan associations' portfolios varies from one form of mortgage to another. For either of the fixed interest rate contracts, the cash flow from the mortgage is constant as long as it has not been prepaid. If the interest rate rises, the homeowner has a nominal capital gain, since his loan is then at a below market interest rate. He would therefore be less likely to prepay. The fall in the savings and loans' net worth arises from two factors: (1) the interest rate differential for mortgages of a fixed duration, and (2) the endogenous lengthening of the duration.

This paper is an attempt to measure the dependence of the duration of mortgages on the implicit unrealized capital gain of mortgage holders resulting from interest rate changes. Our estimate is based on a sample of 4,000 mortgages issued in California which were active in 1975. We follow their payment history from 1975 to 1982. Using a Proportional Hazards Model, we estimate the percentage reduction in prepayment probability associated with interest rate changes. Our results indicate that for due-on-sale fixed interest rate mortgages, a sudden increase in the interest rate from 10 to 15 percent would induce a 23 percent loss in the economic value of the mortgage. If the mortgage were assumable, this loss would be 28 percent. Correspondingly, the 6-year average time to repayment of mortgages at a constant interest rate would be lengthened to nine years for due-on-sale mortgages, and 13-1/2 years for assumable ones.

Professor Jerry Green Department of Economics Harvard University Cambridge, MA 02138 (617) $495-4560$
Professor John B. Shoven Department of Economics Stanford University Stanford, CA 94305 (415) 497-3273 


\section{Introduction}

Saving and loan institutions have experienced extremely difficult times in the last four or five years largely because of the term structure of their assets and liabilities. Most of these institutions hold relatively long term fixed yield mortgage assets, while their liabilities are fairly short term savings accounts. Both long and short term interest rates rose in the 1980-82 period above their level in the preceding period. This depressed the value of the saving and loans' mortgage assets, causing the net worth of many of these institutions to become negative. This fact, however, was somewhat disguised by standard accounting conventions which do not mark assets to their market value. In addition to the negative net worth situation, the institutions faced severe cash flow problems caused by the higher interest rates on liabilities and the reduced prepayment experience on mortgages.

The purpose of this study is more limited than an overall assessment of the economic position of the saving and loans. Our purpose is to look at the nature of the mortgage asset itself and ask what determines the probability that the mortgage will be paid off at a particular time or age. For years, the industry has seemingly worked with "rules of thumb." At one time, the conventional assumption was that mortgages would, on average, be paid of $f$ in seven years. The rule currently seems to be 12 years. We want to judge whether these rules are adequate for valuing a mortgage portfolio and, implicitly, what caused the "rule" to change from seven to 12 years?

A mortgage asset is similar to an annuity. The owner receives a fixed stream of dollars for the life of the contract (or, in the case of an annuity, over the life of the owner). The value of both assets is sensitive 
to interest rate fluctuations. A change in the interest or discount rate from ten to 11 percent, for example, will change the nominal value of a 30 year annuity or mortgage by almost ten percent. There are key institutional differences between mortgage assets and annuities, however. First, the mortgage borrower is usually free to buy out of the contract, subject to some modest prepayment penalties, if interest rates fall. It is as if the lending institution had sold a call option to the borrower on its mortgage asset at the time the contract was agreed upon. Presumably this call feature is priced in the interest rate and other terms of the mortgage. Second, most mortgages have traditionally had a due-on-sale clause, meaning that the lender could claim the face value of the mortgage if the borrower sells the residence. If interest rates are lower than the contracted rate of the mortgage at the time of the sale, this option of the lender will not be enforced. However, if the prevailing rate is higher than the contracted rate, the homeowner is forced to give up a below-market loan should he sell the house. This sacrifice or "1ock-in" presumably affects the likelihood of selling and therefore the effective expected maturity of the mortgage asset and its value. One would not expect people to switch houses as frequently if they would have to exchange their low interest rate mortgage for a new one at the higher market rates. The point is that the effective maturity of the mortgage asset is endogenous to the evolution of interest rates and, perhaps, other economic variables.

The main goal of our research has been to estimate the sensitivity of mortgage prepayments to prevailing interest rates. The subject is of immediate importance because of the precarious financial condition of saving and loan and saving bank institutions in the U.S. Since due-on-sale fixed-interest rate mortgages play a major role in their portfolios, assessing their economic net worth position requires valuation of these assets which, in turn, depends on their effective or expected maturity. 
One reason why assessing the net worth of the saving and loan financial intermediaries is of current importance is the level of merger activity in the industry. In a fair number of these mergers effective subsidies have been made to the acquiring institution by the FSLIC or FDIC. The subsidy is deemed necessary to entice the purchaser to absorb a weak institution. All parties in such arrangements need to be able to access the true net worth of the acquired institution. Another demand for mortgage valuation comes from financial markets. Not only is there merger activity in the intermediaries themselves, but there also are financial instruments such as pass-through certificates, mortgage backed bonds, and REITs which must be priced in markets. The sensitivity of mortgage values to interest rate changes is clearly important in this determination. In addition to the standard negative relationship between valuation and interest rates as with fixed term bonds, mortgage assets have the interest effect on maturity which is the subject of our study.

There has been a great deal of activity recently with respect to due-on-sale clauses and their enforceability. In 1978 the case of Cynthia J. Wellenkamp v. Bank of America, et al. prohibited the use of due-on-sale clauses for the sole purpose of raising mortgage rates. By denying those owning mortgage assets of their option to collect face value on sale of the residence, a claim of substantial value was transferred from the lending institutions to mortgage holders. Dietrich (1982) estimated that the loss in mortgage value due to the unenforceability of DOS clauses amounted to more than the total net worth for state-chartered California S\&Ls in 1981. He figured that the value of the mortgage portfolios of the California institutions was reduced by 9.3 percent by this one action. More recently, of course, the U.S. Supreme Court found in 1982 that DOS clauses are 
enforceable for federally chartered institutions. It is unclear whether the legal aspects are completely settled at this time, but the episode vividly demonstrated the value of the DOS provision to lending organizations.

The approach we have taken is to collect data on Individual mortgages and analyze their prepayment experience. A large part of our effort has gone into the collection of the data itself. We have followed the prepayment experience of almost 4,000 mortgages of two California saving and loans for the eight years 1975-1982. What we then estimate is a life-table for mortgages. The analogy with mortality tables is rather complete. We compute for each $\mathbf{n}$ $(n=0,1, \ldots, 29)$ the conditional probabilities of a mortgage which has been outstanding $n$ years of being paid off in the $(\ddot{n}+1)$ st year. The sensitivity of this probability series to the "lock-in" effect of interest rates is estimated. An analogy would be calculating the effect of certain climactic changes on mortality. The estimation techniques used are identical to those used by demographers for life tables.

The next section of the paper presents the methodology and estimation procedure we utilize. Then, the third section describes our data set in some detail. The fourth section presents the estimation results and our interpretation of them. We conclude with some observations on the usefulness of the informatinn we have learned. 


\section{Methodology}

We want to estimate the effect of changes in interest rates on the turnover rates of mortgages. It is most important to recognize that the primary determinants of the decision to sell a house are not related to interest rate fluctuations. They are largely concerned with the personal circumstances of the owner: Job changes, births of children, changes in family income or wealth, changes in taste for the type of housing, divorce, marriage, etc. We have no way of knowing why any given mortgage did or did not turn over in a given year. The only evidence of individual characteristics that we do have is the length of tenure in the house.

There are, thus, two relevant variables in our study: length of tenure in the house, and an imputed "recapitalized" or "market" value of the mortgages. We want to estimate the probability of turnover at each tenure as a function of the relationship between this "market" value of the mortgage and its remaining principal balance.

Estimating the effect of the interest rate lock-in on mortgage prepayments presents the problem of a time varying covariate. In addition, the fact that much of the sample remained alive in 1982 (the last year of observation), gives us the commonly encountered econometric problem of a censored sample. Below we discuss these problems in detail and describe our econometric method. 
The Problem of Parameterization and Sample Size

The most flexible specification would allow for a different hazard function for each value of the exogenous variables affecting turnover. However, estimating separate life tables for each risk-exposure category would require vastly more data than we have available. Let us suppose that we divided the interest rate differentials or lock-in magnitudes into five or ten groups. The sample size within each group would be less than 1,000. For some ages, particularly those beyond ten years from date of issue, the number of mortgages at risk would be too low to permit an accurate assessment of their turnover rate. Separating the sample in this way, :..even if it were possible, would implicitly assume that there is no relationship at all between the turnover rates at the same age for various interest rate differentials. But economic theory and common sense tell us that the extent of the lock-in effect should be increasing in the interest rate differential. An accurate estimation procedure should take these restrictions into account.

Moreover, even though we have quite a large sample, the number of parameters that would have to be estimated by the separate group method would be beyond what the data could reliably provide. More structure, that is to say, a more parsimonious parameterization is needed. We employ the Proportional Hazards Model, which is widely used in demography and medical research, as well as in economics. ${ }^{1}$ Under the Proportional Hazards Hypothesis, the probability of a turnover can be divided into two multiplicative factors as follows:

probability of turnover of mortgage age (a) if exogenous factors are $x_{1}, \ldots, x_{n}$ at time $t$ $=\lambda(a) \cdot \pi\left(x_{1}, \ldots, x_{n}\right)$

${ }^{1}$ See Heckman and Singer (1982a and 1982b). 
Here $\lambda(a)$ is the "base line hazard" -- that proportion of the population that would turn over even under completely stationary, homogeneous conditions. The second factor, $\pi\left(x_{1}, \ldots, x_{n}\right)$ is greater or less than one according to whether the exogenous factors $x_{1}, \ldots, x_{n}$ make turnover more or less 1ikely. The essential assumption is that of proportionality. If $x_{1}, \ldots, x_{n}$ make turnover more likely at one age, they have an equiproportional impact at all ages. Finaliy, it is implicit in the above formula that the effect of $x_{1}, \ldots, x_{n}$ on turnover is time-separable. Past attributes of the environment and anticipated future values are assumed not to have any affect on turnover In the present.

We defer a discussion of the functional form of $\pi\left(x_{1}, \ldots, x_{n}\right)$ and the choice of exogenous variables to the section on estimation, below. While we continue to develop the methodology for the general $n$ variable case, In the empirical section we will deal only with the "interest rate lock-in" variable, i.e., $n=1$.

Non-constancy of Factors Affecting Turnover

The standard proportional hazards model is based on the presumption that factors affecting turnover are specific to the individual but do not vary during the period over which the individual is followed in the sample. For instance, in a medical context, a history of previous illness may be known and may be thought relevant to the life expectancy of the patient. The selected method of treatment in a randomized clinical trial would also be such a time-invariant variable.

In our model it is essential to recognize that the differential between an. Imputed "market" value of the loan and the contractual value is fluctuating over time. The holder of a mortgage has an option to prepay, and the value of that option depends on his expectations about the course of future interest rates. We assume that borrowers consider the current value 
of their mortgage in deciding whether or not to prepay. They do not attempt to buy options or futures contracts whose value would fluctuate so as to insulate them from the risks inherent in the mortgage contract. They make their decisions myopically, year by year. For the vast majority of homeowners, this is undoubtedly correct.

This time-separability assumption allows us to estimate the hazard function $\pi\left(x_{1}, \ldots, x_{n}\right)$ even in the time-varying case, by using a maximum likelihood technique that treats each year for each mortgage as a separate observation whose value is the binary decision: prepay or do not prepay. The details are given in the estimation section.

\section{Estimation}

The Proportional Hazards Model described above is implemented by parameterizing the function $\pi$ as follows:

$$
\pi\left(x_{1}, \ldots, x_{n}\right)=e^{\sum_{i=1}^{n} B_{i} x_{i}} .
$$

We first discuss the estimation of the coefficients $\beta_{1}, \ldots, \beta_{n}$ when the exogenous variables $x_{1}, \ldots, x_{n}$ are fixed for each mortgage. of course, as interest rates do vary, that is not the case. A more general estimation procedure is necessary for the time-varying case. We discuss this subsequently. The data in the time-invariant case gives, for each observation, the issue date of the mortgage, its termination date if it was prepaid, the original interest rate, and the original principal amount. From this we compute the magnitudes actually used as the exogenous $x$ variables in the hazard function. If the mortgage was still active at the time our data collection stopped, the 
observation is referred to as "censored;" if it has been prepaid, we refer to its age at prepayment as the "failure age."

A typical mortgage will be denoted by the subscript $l$, and the total number of mortgages is $k$, thus we let $l=1, \ldots, k$. The data relevant to each mortgage is a vector of $n$ numbers which may vary over the lifetime of the mortgage. At calendar time $t$, the characteristics of mortgage $l$ are described by

$$
x_{\ell t}=\left(x_{1 \ell t}, \ldots, x_{n \ell t}\right)
$$

For each mortgage, $t$ runs from its issue date to the termination date. If it is observed to be prepaid, the last $t$ is the prepayment date; if it is not prepaid, the last $t$ is the date of our study, that is 1982 .

Because the maximum possible age of a mortgage is 30 years, we let $1=1, \ldots, 30$ describe the age of the mortgage at termination, whether this is a prepayment ("failure") or a non-prepayment as of 1982 ("censored"). For each 1 , let $D_{1}$ be the set of mortgages that failed at age 1 , and let $d_{1}$ be the number of mortgages in $D_{1}$. Let $R_{1}$ be the set of mortgages at risk of failure at age 1 ; that is, the mortgages that did not fall at any age less than 1 . Since, at age $i$, some mortgages fail and some do not, $D_{1}$ is a subset of $R_{1}$.

We now describe the $10 \mathrm{~g}-1$ ikelihood of a given sample. It is a function of the vector of parameters $\left(\beta=\beta_{1}, \ldots, \beta_{n}\right)$ that correspond to the influence of each of the $n$ characteristics of mortgage $l$ at time $t, x_{\ell t}=\left(x_{1 \ell t}, \ldots, x_{n \ell t}\right)$. In vector notation, the Proportional Hazards Model (2) is written

$$
\pi(x)=e^{\beta \cdot x}
$$

The log likelihood is factored into a part due age alone and the part above 
due to the variables $x$. The parameters $\beta$ are found by maximizing the second of these parts.

Kalbfleish and Prentice (1980) present an approximation to this expression, known as the partial likelihood. Let

$$
s_{i}=\sum_{\ell \varepsilon D_{1}} x_{\ell t_{\ell}}
$$

where $t_{\ell}$ is the calendar time at which mortgage $\ell$ failed (i.e., it was age 1 ). The log partial likelihood is

$$
\sum_{i=1}^{30} s_{i}^{\beta}-d_{i}\left\{\log \sum_{\ell \in R(i)} e^{x_{\ell t}{ }^{\beta}}\right\}
$$

where $t_{\ell i}$ is the calendar time at which mortgage $\ell$ is age 1 . (Kalbfleish and Prentice discuss this partial likelihood method in their Chapter 4, Section 4.2.2.)

Given an estimate of $\beta$, we can estimate the hazard for a mortgage age $i$ whose characteristics are $x_{\ell t_{\ell 1}}$, which is

$$
\lambda_{i} e^{x_{\ell t_{l i}}} \cdot \beta
$$

by a second maximum likelihood method. Defining $\alpha_{i}=1-\lambda_{i}$ as the baseline survival probability at each age $i$, the overall likelihood of the sample is

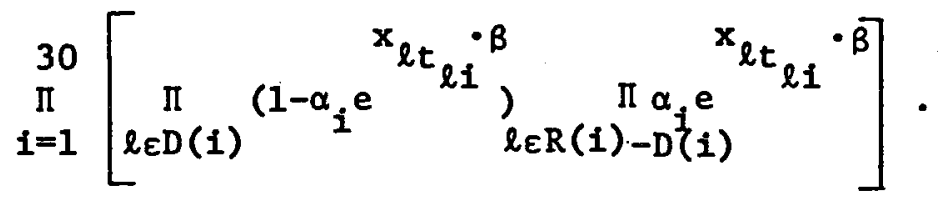

(Kalbfleish and Prentice present an iterative method for the maximiation of (5) with respect to $\left(\alpha_{1}, \ldots, \alpha_{30}\right)$ in Chapter 4 , Section 4.3.) 
The likelihood functions, equations (3) and (5), are maximized by an iterative Gaussian or Newton-type technique. The approach is to make a first guess or estimate of $\alpha$ or $\beta$, calculate the first derivatives of the log likelihood function and the matrix of second partials and solve the linearized system of equations for a zero of the first derivatives. This will give a "next guess" value for $\alpha$ or $\beta$ which meet the first order conditions for a maximum, except that the assumed linearity of the first derivatives is inaccurate. The procedure is repeated until convergence is achieved. It should be noted that only local maxima are calculated from this type of procedure and that multiple equilibria are a real possibility. We have not experienced this problem as far as we can tell, but it cannot be ruled out a priori. A principal advantage of the Proportional Hazard specification is that the maximum likelihood estimate of $B$ is separable from the estimation of the baseline hazard function $\lambda(a)$. Therefore, $\beta$ is computed first and $\lambda(a)$ is computed by a separate maximum likelihood routine holding $B$ fixed.

The key covariate $(x)$ for our analysis is a measure of the lock-in caused by an interest rate differential between that prevaling in the mortgage market and the contracted rate of the mortgage. We considered a number of specifications of this phenomenon. The most straightforward, of course, would simply be the dollar value difference between the two valuations. We felt that this was not the correct specification since a $\$ 15,000$ lock-in presumably affects the owner of a $\$ 60,000$ dwelling more than someone who owns a $\$ 300,000$ home. It was our feeling that the prepayment probability was probably affected by the percentage of the lock-in relative to the value of the house. The lock-in effect can be thought of as a transaction cost of moving similar to the brokers fees (which traditionally are five or six percent). Unfortunately, one piece of information not in our data set 
is the market value of the dwelling. What we have done is create a lock-in variable defined as the difference between the face and market values of the mortgage (where the market value is calculated using current mortgage rates for the full remaining life of the mortgage) divided by the initial principal amount updated by the ratio of the price index for housing to its level at the time of issuance. This gives us a proxy for the percentage lock-in relative to the "real" initial mortgage amount. If households financed similar proportions of their purchase, then it would be proportional to our preferred lock-in measure. As it stands, this measure imperfectly captures what we would expect to be most closely related to prepayment behavior, but it seems the most satisfactory available option given the data. 


\section{Data Set}

The data set contains 3,938 mortgages held by two large California Savings and Loan Associations. A sample of mortgages active in a base year was selected and followed through 1982. The base year in each case was chosen on the basis of data availability; for the first association, data were available beginning in 1975 and for the second association, data were available in 1976. The mortgages were all issued for California homes and all areas of the State were represented. Officlals at both S\&Ls believe their portfolios are typical of those of California savings and loans. (The data set we assembled with identifiers removed can be obtained by writing the authors.)

Approximately 52 percent of the sample came from the first association. Extensive information was available regarding the active mortgages, including original mortgage amount, interest rate, principal and interest payments, current principal balance, payment history, loan-to-value ratio, term, and due date. Information on paid off mortgages was much more limited; usually interest rate, principal and interest payment, balance at payoff, and date of payoff were available. The sample consists primarily of conventional mortgages, although some VA and FHA mortgages are included. All of the mortgages have fixed interest rates.

The remaining 48 percent of the sample came from the second association. Eighty-four percent are conventional mortgages, ten percent are VA mortgages, and six percent are FHA mortgages. Information available on the active mortgages included principal amount, interest rate, monthly principal and interest payment, issue date, mortgage type, and impounds. For paid off 
mortgages, data include interest rate, principal and interest payment, mortgage type, and payoff date.

While we know the aggregate proportions for conventional, FHA, and VA mortgages, we do not know which individual mortgages are of which type. This is unfortunate, since VA and FHA loans are contractually assumable and should, therefore, be treated separately. Obtaining this information for our data set is difficult or impossible at this point, but this problem should be recognized in designing similar studies in the future. The effect of this mixture of mortgages on our estimates will be discussed below.

Our data set is described in Tables 1 and 2. The first of these shows the age and payoff distribution for the entire set. Of the 3,938 mortgages, 2,037 were paid off in the 1975 to 1982 period, while 1,901 were still active at the end of 1982. Most of our mortgages were issued between 1962 and 1975 , and thus were ages 0 through 20 in the 1975 to 1982 interval. Table 2 gives descriptive data for the sample by mortgage issue year. The rising pattern of interest rates is shown, as is the concentration of the sample (in terms of total principal amount) in mortgages issued between 1970 and 1975 .

There are a number of problems with the data set. Among the relatively minor, technical difficulties, issue dates for paid off mortgages had to be estimated by loan number. At both associations, numbers are assigned to loans chronologically within large groups of numbers, so paid off mortgages were assigned the issue dates of active mortgages with similar loan numbers. This method of dating is not precise, and some mistakes were surely made, but it is unlikely that any assigned issue year is off by more than one year in either direction. Original mortgage amounts were not always available for paid off mortgages, so these vlaues were calculated assuming each mortgage had a 30 year term; almost all active mortgages had 30 year terms, so this is not a bad assumption. 
TABLE 1

PAYOFF EXPERIENCE BY ISSUE YEAR FOR 1975-1982

\begin{tabular}{|c|c|c|c|c|c|c|c|c|c|c|}
\hline $\begin{array}{l}\text { Issue } \\
\text { Year }\end{array}$ & 1975 & 1976 & 1977 & $\begin{array}{c}\text { Payoff } \\
1978\end{array}$ & $\frac{\text { Years }}{1979}$ & 1980 & 1981 & 1982 & Active & $\begin{array}{l}\text { Total } \\
\text { Each } \\
\text { e Row }\end{array}$ \\
\hline 1947 & 0 & 0 & 1 & 0 & 0 & 0 & 0 & 0 & 0 & 1 \\
\hline 51 & 0 & 0 & 0 & 0 & 0 & 1 & 0 & 0 & 0 & 1 \\
\hline 52 & 0 & 0 & 0 & 0 & 0 & 1 & 0 & 0 & 0 & 1 \\
\hline 53 & 0 & 0 & 0 & 0 & 0 & 1 & 0 & 0 & 0 & 1 \\
\hline 54 & 0 & 1 & 0 & 0 & 1 & 1 & 0 & 0 & 4 & 7 \\
\hline 55 & 0 & 0 & 1 & 0 & 2 & 0 & 0 & 0 & 4 & 7 \\
\hline 56 & 1 & 1 & 1 & 1 & 1 & 0 & 0 & 0 & 2 & 7 \\
\hline 57 & 0 & 1 & 3 & 4 & 2 & 0 & 0 & 0 & 5 & 15 \\
\hline 58 & 0 & 3 & 2 & 2 & 3 & 1 & 1 & 0 & 3 & 15 \\
\hline 59 & 1 & 4 & 9 & 6 & 10 & 1 & 0 & 0 & 3 & 34 \\
\hline 60 & 2 & 1 & 13 & 8 & 1 & 0 & 1 & 0 & 9 & 35 \\
\hline 61 & 6 & 5 & 14 & 11 & 6 & 5 & 3 & 3 & 25 & 78 \\
\hline 62 & 9 & 4 & 18 & 10 & 8 & 12 & 4 & 2 & 50 & 117 \\
\hline 63 & 8 & 9 & 33 & 13 & 19 & 6 & 5 & 2 & 104 & 199 \\
\hline 64 & 9 & 11 & 30 & 24 & 11 & 6 & 5 & 2 & 113 & 211 \\
\hline 65 & 6 & 11 & 35 & 20 & 20 & 5 & 3 & 5 & 116 & 221 \\
\hline 66 & 0 & 3 & 13 & 7 & 5 & 3 & 0 & 3 & 62 & 96 \\
\hline 67 & 4 & 5 & 26 & 13 & 13 & 2 & 4 & 2 & 84 & 153 \\
\hline 68 & 5 & 5 & 17 & 9 & 13 & 2 & 0 & 3 & 75 & 129 \\
\hline 69 & 8 & 5 & 19 & 6 & 6 & 8 & 3 & 1 & 70 & 126 \\
\hline 70 & 11 & 18 & 41 & 15 & 19 & 4 & 1 & 0 & 80 & 189 \\
\hline 71 & 21 & 31 & 46 & 22 & 33 & 8 & 4 & 1 & 140 & 306 \\
\hline 72 & 45 & 46 & 81 & 59 & 40 & 14 & 3 & 11 & 292 & 591 \\
\hline 73 & 23 & 40 & 107 & 58 & 37 & 11 & 5 & 7 & 309 & 597 \\
\hline 74 & 17 & 43 & 96 & 43 & 46 & 15 & 3 & 5 & 187 & 455 \\
\hline 75 & 0 & 21 & 67 & 29 & 28 & 8 & 4 & 4 & 132 & 293 \\
\hline 76 & & 0 & 10 & 1 & 7 & 2 & 0 & 1 & 32 & 53 \\
\hline
\end{tabular}


TABLE 2

AVERAGE MORTGAGE SIZE AND INTEREST RATE BY YEAR OF ISSUE

\begin{tabular}{|c|c|c|c|c|c|}
\hline $\begin{array}{l}\text { Issue } \\
\text { Year }\end{array}$ & $\begin{array}{l}\text { Number } \\
\text { of } \\
\text { Mortgages }\end{array}$ & $\begin{array}{l}\text { Total } \\
\text { Principal } \\
\text { Value } \\
\text { (dollars) }\end{array}$ & & $\begin{array}{l}\text { Average } \\
\text { Principal } \\
\text { Value } \\
\text { (dollars) }\end{array}$ & $\begin{array}{l}\text { Average } \\
\text { Interest } \\
\text { Rate }\end{array}$ \\
\hline 1947 & 1 & $\$ 15,267.34$ & $\$$ & $15,267.34$ & 6.50 \\
\hline 51 & 1 & $18,650.00$ & & $18,650.00$ & 5.00 \\
\hline 52 & 1 & $18,650.00$ & & $18,650.00$ & 5.00 \\
\hline 53 & 1 & $18,650.00$ & & $18,650.00$ & 5.00 \\
\hline 54 & 7 & $72,586.68$ & & $10,369.53$ & 5.07 \\
\hline 55 & 7 & $84,294.80$ & & $12,042.12$ & 4.75 \\
\hline 56 & 7 & $93,511.38$ & & $13,358.77$ & 5.78 \\
\hline 57 & 15 & $219,853.42$ & & $14,656.89$ & 5.21 \\
\hline 58 & 15 & $238,614.14$ & & $15,907.61$ & 6.14 \\
\hline 59 & 34 & $844,513.25$ & & $24,838.63$ & 6.46 \\
\hline 60 & 35 & $569,492.31$ & & $16,271.21$ & 6.60 \\
\hline 61 & 78 & $1,540,570.25$ & & $19,750.90$ & 6.40 \\
\hline 62 & 117 & $2,512,234.50$ & & $21,472.09$ & 6.45 \\
\hline 63 & 199 & $5,157,870.50$ & & $25,918.95$ & 6.37 \\
\hline 64 & 211 & $4,909,534.00$ & & $23,267.93$ & 6.43 \\
\hline 65 & 221 & $5,159,343.50$ & & $23,345.45$ & 6.40 \\
\hline 66 & 96 & $2,141,375.25$ & & $22,305.99$ & 6.51 \\
\hline 67 & 153 & $3,688,972.25$ & & $24,110.93$ & 6.56 \\
\hline 68 & 129 & $3,958,028.25$ & & $30,682.39$ & 7.06 \\
\hline 69 & 126 & $3,605,869.25$ & & $28,618.01$ & 7.84 \\
\hline 70 & 189 & $7,119,306.00$ & & $37,668.29$ & 8.27 \\
\hline 71 & 306 & $10,087,308.00$ & & $32,965.06$ & 7.49 \\
\hline 72 & 591 & $20,907,446.00$ & & $35,376.39$ & 7.35 \\
\hline 73 & 597 & $21,036,692.00$ & & $35,237.34$ & 7.75 \\
\hline 74 & 455 & $16,026,642.00$ & & $35,223.39$ & 8.91 \\
\hline 75 & 293 & $11,762,383.00$ & & $40,144.65$ & 9.49 \\
\hline 76 & 53 & $3,755,278.75$ & & $72,216.90$ & 8.56 \\
\hline
\end{tabular}


Another problem involves the sample of "old" (20 year or longer) mortgages. A random sample of 2,000 mortgages active in 1975 will yield few old mortgages because associations currently issue a much larger number of mortgages each year than they did in the 1950s, and most of the mortgages that were issued in the early 1950s were paid off before the base year of 1975 . While mortgages exist for each age, for the longest lives there may be only two or three mortgages available. The sample would have to be either increased drastically or drawn on a stratified basis to correct this problem.

The most severe problem, however, is that the two institutions, while now federally chartered, were state chartered until 1981. Both of them changed the nature of their charter largely because of the Wellenkamp decision regarding the enforceability of due-on-sale clauses. Both institutions included due-onsale clauses in their mortgages and enforced its provisions for single-family home mortgage contracts before the court decision, but were prohibited from doing so thereafter unless they could show that allowing assumption by the purchaser of the house would impair the security of the mortgage due to an increased risk of default. For practical purposes, this meant that the Dos clauses were not enforceable. This situation has been reversed with the DelaCuesta decision and the Garn-St. Germain Act in 1982, but their impact was not effective until after the completion of our data sample.

The approach we have taken is to divide the sample into two periods, 1975-1978, and 1979-1982, and separately estimate for each of these intervals the sensitivity of prepayment experience to interest rate fluctuations. Clearly this reduces the power of our estimation procedures, since it leaves us with a smaller number of observations in each of the two periods, but our estimates are still reasonably precise. It also permits us to judge the effect of the Wellenkamp decision on prepayment experience and hence the valuation of mortgage portfolios. 


\section{Results}

In our empirical work, we have used the Proportional Hazards Model with one variable. The lock-in variable is defined as

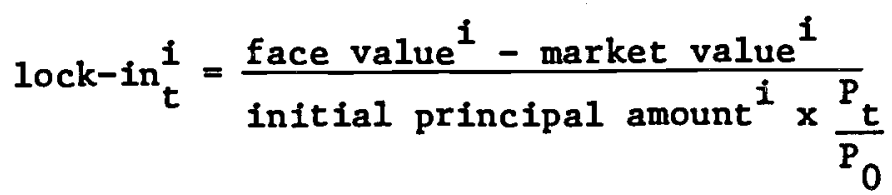

where $P_{t}$ is a price index for residential housing at time $t$ and $P_{0}$ is that index at the time the mortgage was issued.

This lock-in measure is calculated for each mortgage still alive in each year during the 1975-1982 interval.' Since the mortgages in our sample were issued between 1947 and 1976, mortgages of all ages are observed. Tables 3 and 4 show the number of mortgages which reached each age in the 1975-1978 and the 1979-1982 interval respectively. Again, the data are separated in this way because of the Wellenkamp decision. Any mortgage which reached a particular age in the interval of observation is termed "at risk." The number of mortgages which were at risk for each age is shown in the first column of Tables 3 and 4. The number which prepaid (or "died") is shown in the second columns. The third and fourth columns report the average lock-in for all at risk mortgages and for only those which prepaid, respectively. Interestingly, the average lock-in is lower for those mortgages which paid off for almost every age in both the pre-Wellenkamp period and in the 1979-1982 interval. This gives some preliminary indication that interest rate lock-in may be an important determinant of prepayment probabilities.

The maximum likelihood estimates confirm this preliminary finding and also allow us to measure the impact of the Wellenkamp decision. The estimate for $B$ in the pre-Wellenkamp period is -4.37 with a standard error of . 55, while 
TABLE 3

LOCK-IN BY MORTGAGE AGE FOR THOSE PAID OFF AND FOR ALL AT RISK 1975-1978

\begin{tabular}{|c|c|c|c|c|}
\hline $\begin{array}{l}\text { Mortgage } \\
\text { Age }\end{array}$ & $\begin{array}{l}\text { Nbr. at } \\
\text { Risk }\end{array}$ & $\begin{array}{l}\text { Nbr. Paid } \\
\text { Off }\end{array}$ & $\begin{array}{l}\text { Average } \\
\text { Lock-in } \\
\text { for Those } \\
\text { at Risk } \\
\quad(\%)\end{array}$ & $\begin{array}{l}\text { Average } \\
\text { Lock-1n } \\
\text { for Those } \\
\text { Paid Off } \\
(\%)\end{array}$ \\
\hline 1 & 800 & 47 & 0.12 & 0.69 \\
\hline 2 & 1350 & 134 & 4.23 & 2.44 \\
\hline 3 & 1765 & 210 & 6.98 & 4.80 \\
\hline 4 & 1685 & 217 & 8.52 & 7.23 \\
\hline 5 & 1401 & 181 & 9.07 & 9.07 \\
\hline 6 & 977 & 131 & 8.68 & 9.04 \\
\hline 7 & 615 & 73 & 7.41 & 6.23 \\
\hline 8 & 509 & 43 & 7.62 & 6.20 \\
\hline 9 & 458 & 28 & 8.35 & 7.29 \\
\hline 10 & 563 & 44 & 8.92 & 8.37 \\
\hline 11 & 637 & 46 & 8.57 & 7.97 \\
\hline 12 & 685 & 61 & 7.96 & 7.30 \\
\hline 13 & 668 & 68 & 7.45 & 7.05 \\
\hline 14 & 529 & 67 & 6.87 & 6.00 \\
\hline 15 & 360 & 38 & 6.41 & 5.64 \\
\hline 16 & 220 & 26 & 5.75 & 5.09 \\
\hline 17 & 133 & 28 & 5.16 & 4.73 \\
\hline 18 & 78 & 20 & 4.75 & 3.74 \\
\hline 19 & 54 & 10 & 4.56 & 4.13 \\
\hline 20 & 37 & 6 & 4.24 & 3.94 \\
\hline 21 & 30 & 5 & 3.83 & 3.35 \\
\hline 22 & 19 & 3 & 3.11 & 2.44 \\
\hline 23 & 14 & 0 & 2.66 & 0.00 \\
\hline 24 & 9 & 0 & 2.08 & 0.00 \\
\hline 25 & 4 & 0 & 1.47 & 0.00 \\
\hline 26 & 4 & 0 & 1.02 & 0.00 \\
\hline 27 & 3 & 0 & 0.63 & 0.00 \\
\hline 28 & 3 & 0 & 0.31 & 0.00 \\
\hline 29 & 2 & 0 & 0.10 & 0.00 \\
\hline 30 & 1 & 0 & 0.00 & 0.00 \\
\hline
\end{tabular}


TABLE 4

LOCK-IN BY MORTGAGE AGE FOR THOSE PAID OFF AND FOR ALL AT RISK 1979-1982

\begin{tabular}{|c|c|c|c|c|}
\hline $\begin{array}{l}\text { Mortgage } \\
\text { Age }\end{array}$ & $\begin{array}{l}\text { Nbr. at } \\
\text { Risk }\end{array}$ & $\begin{array}{l}\text { Nbr. Paid } \\
\text { Off }\end{array}$ & $\begin{array}{l}\text { Average } \\
\text { Lock-in } \\
\text { for Those } \\
\text { at Risk } \\
(\%)\end{array}$ & $\begin{array}{l}\text { Average } \\
\text { Lock-in } \\
\text { for Those } \\
\text { Paid off } \\
\quad(\%)\end{array}$ \\
\hline 1 & 0 & 0 & $\cdot \cdot \cdot$ & . $\cdot$ \\
\hline 2 & 0 & 0 & $\cdot \cdot \cdot$ & . • \\
\hline 3 & 42 & 7 & 15.019 & 14.785 \\
\hline 4 & 211 & 30 & 10.424 & 13.050 \\
\hline 5 & 437 & 54 & 13.186 & 12.465 \\
\hline 6 & 752 & 57 & 16.108 & 14.998 \\
\hline 7 & 1023 & 58 & 17.077 & 15.497 \\
\hline 8 & 1019 & 57 & 17.896 & 14.729 \\
\hline 9 & 879 & 37 & 17.812 & 13.881 \\
\hline 10 & 621 & 25 & 16.459 & 15.874 \\
\hline 11 & 397 & 23 & 14.013 & 11.014 \\
\hline 12 & 339 & 18 & 12.357 & 10.952 \\
\hline 13 & 314 & 8 & 11.883 & 10.257 \\
\hline 14 & 385 & 30 & 10.836 & 9.540 \\
\hline 15 & 393 & 18 & 10.152 & 8.590 \\
\hline 16 & 321 & 31 & 9.990 & 8.110 \\
\hline 17 & 248 & 24 & 9.516 & 8.170 \\
\hline 18 & 114 & 25 & 8.486 & 7.480 \\
\hline 19 & 209 & 12 & 7.677 & 7.221 \\
\hline 20 & 107 & 15 & 6.678 & 5.458 \\
\hline 21 & 50 & 8 & 5.709 & 4.969 \\
\hline 22 & 24 & 3 & 4.570 & 3.767 \\
\hline 23 & 15 & 2 & 3.768 & 3.307 \\
\hline 24 & 16 & 2 & 2.906 & 2.350 \\
\hline 25 & 17 & 2 & 2.118 & 1.452 \\
\hline 26 & 12 & 1 & 1.580 & 1.426 \\
\hline 27 & 10 & 1 & 1.049 & 0.893 \\
\hline 28 & 6 & 1 & 0.532 & 0.464 \\
\hline 29 & 1 & 1 & 0.164 & 0.164 \\
\hline
\end{tabular}


the figure for the $1979-82$ period is -13.07 with a standard error of 1.37 . To aid in interpreting these numbers, note that they indicate that a modest ten percent lock-in would have reduced prepayment probabilities by 33 percent in the due-on-sale period $1975-78$ and by 63 percent in 1979-82. The results indicate that even in a due-on-sale regime, the likelihood of prepayment depends on the relationship between the contractual rate on the mortgage and the market rate. In the period when the due-on-sale clause was unenforceable, the prepayment experience was even more sensitive to interest rates. In that period, prepayment would seldom occur unless the buyer could for some reason not asssume the loan. Also, for older mortgages the lock-in is smaller (relative to the current cost of the house) and therefore the loan may be prepaid at the time of sale.

Recall that a small fraction of our mortgages were FHA and VA loans which are contractually assumable. This would bias the estimate in the 1975-78 interval upwards in absolute value. Therefore, the large effect we attribute to the Wellenkamp decision may be underestimated. 1

The estimated base line hazard as a function of mortgage age is shown in Table 5. The hazards for the first 18 years or so are estimated with reasonable precision, while for mortages older than that the relative scarcity of data means that the hazard cannot be precisely determined.

Tables 6 and 7 show the sensitivity to market interest rates of the cash flow (interest plus principal plus prepayments) from $\$ 1,000,000$ of ten percent 30 year mortgages. The first of these tables is calculated for the 1975-78 period and hence with $B=-4.37$. If interest rates climb to 15 percent, the pattern of the cash flow from the ten percent mortgages is changed significantly. For instance, the cash flow from the mortgages at age two is reduced from $\$ 203,455$ to $\$ 138,401$. This is due entirely to the reduced prepayment 
TABLE 5

CONDITIONAL PAYOFF PROBABILITIES AS A FUNCTION OF MORTGAGE AGE

\begin{tabular}{|c|c|c|}
\hline Age & $\begin{array}{c}\text { Estimated Hazard } \\
\text { Function } \\
\lambda(a) \\
(\%)\end{array}$ & $\begin{array}{c}\text { Standard Deviation } \\
(\%)\end{array}$ \\
\hline 1 & 5.59 & 0.79 \\
\hline 2 & 11.18 & 0.91 \\
\hline 3 & 15.34 & 0.97 \\
\hline 4 & 17.99 & 1.10 \\
\hline 5 & 18.38 & 1.23 \\
\hline 6 & 18.67 & 1.46 \\
\hline 7 & 15.85 & 1.70 \\
\hline 8 & 11.52 & 1.65 \\
\hline 9 & 8.66 & 1.56 \\
\hline 10 & 11.29 & 1.60 \\
\hline 11 & 10.31 & 1.44 \\
\hline 12 & 12.36 & 1.48 \\
\hline 13 & 13.80 & 1.55 \\
\hline 14 & 16.73 & 1.86 \\
\hline 15 & 13.73 & 2.06 \\
\hline 16 & 14.93 & 2.69 \\
\hline 17 & 25.65 & 4.17 \\
\hline 18 & 30.70 & 5.71 \\
\hline 19 & 22.15 & 6.17 \\
\hline 20 & 19.19 & 7.04 \\
\hline 21 & 19.41 & 7.79 \\
\hline 22 & 17.91 & 9.37 \\
\hline 23 & 20.92 & 13.09 \\
\hline 24 & 17.79 & 11.36 \\
\hline 25 & 7.70 & 7.39 \\
\hline 26 & 10.15 & 9.61 \\
\hline 27 & 11.39 & 10.70 \\
\hline 28 & 17.77 & 16.11 \\
\hline
\end{tabular}


TABLE 6

CASH FLOWS FROM $\$ 1,000,000$ IN 10\% MORTGAGES AS A FUNCTION OF AGE AND MARKET INTEREST RATES

(for $1975-78 ; B=-4.37$ )

\begin{tabular}{|c|c|c|c|c|c|c|}
\hline Age & $10 \%$ & $11 \%$ & $12 \%$ & $13 \%$ & $14 \%$ & $15 \%$ \\
\hline 1 & 160,876 & 145,890 & 136,169 & 129,587 & 124,964 & 121,615 \\
\hline 2 & 203,455 & 180,731 & 164,629 & 153,095 & 144,676 & 138,401 \\
\hline 3 & 214,042 & 196,028 & 180,574 & 168,187 & 158,470 & 150,865 \\
\hline 4 & 198,497 & 191,944 & 182,585 & 173,158 & 164,731 & 157,560 \\
\hline 5 & 164,049 & 168,788 & 167,885 & 164,162 & 159,425 & 154,613 \\
\hline 6 & 134,341 & 145,630 & 151,147 & 152,613 & 151,694 & 149,576 \\
\hline 7 & 98,271 & 111,622 & 121,011 & 126,813 & 129,918 & 131,218 \\
\hline 8 & 69,058 & 81,155 & 91,144 & 98,744 & 104,187 & 107,920 \\
\hline 9 & 53,156 & 63,741 & 73,202 & 81,091 & 87,354 & 92,173 \\
\hline 10 & 54,448 & 65,712 & 75,977 & 84,689 & 91,696 & 97,124 \\
\hline 11 & 45,850 & 56,001 & 65,654 & 74,254 & 81,540 & 87,497 \\
\hline 12 & 44,468 & 54,678 & 64,606 & 73,667 & 81,531 & 88,105 \\
\hline 13 & 40,790 & 50,533 & 60,253 & 69,388 & 77,569 & 84,627 \\
\hline 14 & 38,527 & 48,039 & 57,739 & 67,092 & 75,702 & 83,341 \\
\hline 15 & 28,405 & 35,700 & 43,349 & 50,979 & 58,279 & 65,036 \\
\hline 16 & 25,170 & 31,764 & 38,778 & 45,897 & 52,844 & 59,412 \\
\hline 17 & 28,772 & 36,402 & 44,588 & 52,982 & 61,269 & 69,202 \\
\hline 18 & 23,440 & 29,799 & 36,738 & 44,005 & 51,361 & 58,601 \\
\hline 19 & 12,811 & 16,357 & 20,286 & 24,482 & 28,830 & 33,226 \\
\hline 20 & 8,914 & 11,401 & 14,174 & 17,158 & 20,281 & 23,475 \\
\hline 21 & 7,001 & 8,963 & 11,158 & 13,530 & 16,026 & 18,594 \\
\hline 22 & 5,209 & 6,673 & 8,315 & 10,095 & 11,975 & 13,918 \\
\hline 23 & 4,413 & 5,656 & 7,051 & 8,566 & 10,170 & 11,832 \\
\hline 24 & 3,069 & 3,935 & 4,907 & 5,966 & 7,088 & 8,253 \\
\hline 25 & 1,837 & 2,355 & 2,938 & 3,573 & 4,247 & 4,948 \\
\hline 26 & 1,734 & 2,224 & 2,775 & 3,375 & 4,012 & 4,674 \\
\hline 27 & 1,513 & 1,940 & 2,421 & 2,944 & 3,500 & 4,079 \\
\hline 28 & 1,367 & 1,753 & 2,187 & 2,660 & 3,162 & 3,685 \\
\hline 29 & 859 & 1,102 & 1,375 & 1,672 & 1,988 & 2,317 \\
\hline 30 & 859 & 1,102 & 1,375 & 1,672 & 1,988 & 2,317 \\
\hline
\end{tabular}


TABLE 7

CASH FLOWS FROM $\$ 1,000,000$ IN 10\% MORTGAGES AS A FUNCTION OF AGE AND MARKET INTEREST RATES

(for $1979-82 ; B=-13.07$ )

\begin{tabular}{|c|c|c|c|c|c|c|}
\hline Age & $10 \%$ & $11 \%$ & $12 \%$ & $13 \%$ & $14 \%$ & $15 \%$ \\
\hline 1 & 160,876 & 127,068 & 115,000 & 110,152 & 108,000 & 106,960 \\
\hline 2 & 203,455 & 148,650 & 125,723 & 115,816 & 111,200 & 108,881 \\
\hline 3 & 214,042 & 163,271 & 134,821 & 121,187 & 114,474 & 110,969 \\
\hline 4 & 198,497 & 169,164 & 141,258 & 125,695 & 117,494 & 113,026 \\
\hline 5 & 164,049 & 162,232 & 141,970 & 127,507 & 119,136 & 114,337 \\
\hline 6 & 134,341 & 125,692 & 141,562 & 129,070 & 120,822 & 115,777 \\
\hline 7 & 98,271 & 128,786 & 130,650 & 124,216 & 118,552 & 114,679 \\
\hline 8 & 69,058 & 101,673 & 113,879 & 114,732 & 113,041 & 111,319 \\
\hline 9 & 53,156 & 84,284 & 101,664 & 107,359 & 108,613 & 108,568 \\
\hline 10 & 54,448 & 88,255 & 107,826 & 113,554 & 113,884 & 112,832 \\
\hline 11 & 45,850 & 77,854 & 100,260 & 109,313 & 111,706 & 111,767 \\
\hline 12 & 44,468 & 77,503 & 102,623 & 113,405 & 116,146 & 115,911 \\
\hline 13 & 40,790 & 73,303 & 100,933 & 114,527 & 118,739 & 118,980 \\
\hline 14 & 38,527 & 71,137 & 101,709 & 118,612 & 124,546 & 125,211 \\
\hline 15 & 28,405 & 54,312 & 82,348 & 101,816 & 111,760 & 115,849 \\
\hline 16 & 25,170 & 49,023 & 76,801 & 98,227 & 110,564 & 116,437 \\
\hline 17 & 28,772 & 56,680 & 90,587 & 118,052 & 134,181 & 141,390 \\
\hline 18 & 23,440 & 47,218 & 78,940 & 108,779 & 130,011 & 142,283 \\
\hline 19 & 12,811 & 26,341 & 46,084 & 67,773 & 86,859 & 101,295 \\
\hline 20 & 8,914 & 18,482 & 32,978 & 50,044 & 66,607 & 80,704 \\
\hline 21 & 7,001 & 14,582 & 26,308 & 40,664 & 55,418 & 68,889 \\
\hline 22 & 5,209 & 10,884 & 19,795 & 31,025 & 43,086 & 54,739 \\
\hline 23 & 4,413 & 9,238 & 16,877 & 26,663 & 37,445 & 48,215 \\
\hline 24 & 3,069 & 6,435 & 11,802 & 18,779 & 26,647 & 34,759 \\
\hline 25 & 1,837 & 3,854 & 7,086 & 11,326 & 16,180 & 21,291 \\
\hline 26 & 1,734 & 3,640 & 6,696 & 10,712 & 15,322 & 20,193 \\
\hline 27 & 1,513 & 3,176 & 5,845 & 9,357 & 13,400 & 17,688 \\
\hline 28 & 1,367 & 2,869 & 5,281 & 8,459 & 12,122 & 16,016 \\
\hline 29 & 859 & 1,804 & 3,321 & 5,321 & 7,629 & 10,087 \\
\hline 30 & 859 & 1,804 & 3,321 & 5,321 & 7,629 & 10,087 \\
\hline
\end{tabular}


experience. The cash flow is higher at 15 percent than at ten percent for older mortgages because more of the mortgages survive to these ages. For instance, at 20 years, the cash flow at ten percent is $\$ 8,914$, whereas at 15 percent, it is $\$ 23,475$.

During the 1979-82 Wellenkamp period, this sensitivity of cash flows to interest rates was greatly increased as is evidenced by Table 7 . In this period, $\$ 1,000,000$ of ten percent mortgages could be expected to generate $\$ 203,455$ at age 2 with interest rates at ten percent, but only $\$ 108,881$ at 15 percent interest. At age 20 , the numbers are $\$ 8,914$ at ten percent versus $\$ 80,704$ at 15 percent. This nire to one ratio reflects the vastly greater interest payments from the much greater number of old mortgages in the 15 percent case.

These cash flows can be put in perspective by calculating their present value at the time of issue. This is done in rable 8 . It shows that as market interest rates rise from ten percent to 15 percent, the value of the mortgages falls 22.74 percent if they are due-on-sale and 28.10 percent if that clause cannot be enforced. Both numbers exceed the fall in value that would be experienced by a fixed maturity instrument of the same duration, of course, but the interesting thing to note is the very significant difference between the effects in the two regimes. The loss with 15 percent interest is 23.6 percent greater in the Wellenkamp era, resulting in the mortgages losing 5.36 percent of their value over and above what they would have lost in a due-on-sale environment. This 5.36 percent difference could easily eliminate the net equity position of a savings and loan. Thus, the table indicates both that the value of mortgages is highly sensitive to interest rates and that this value depends significantly on the rules regarding due-on-sale. 
TABLE 8

PRESENT VALUE OF 10\% MORTGAGE CASH FLOWS AS A FUNCTION OF MORTGAGE INTEREST RATES

\begin{tabular}{|c|c|c|c|c|c|c|}
\hline & $10 \%$ & $11 \%$ & $12 \%$ & $13 \%$ & $14 \%$ & $15 \%$ \\
\hline$B=-4.37 ; 1975-78$ & 995,483 & 951,491 & 905,240 & 858,571 & 812,863 & 769,083 \\
\hline (loss as \% of original PV) & $\cdot \cdot \cdot$ & 4.42 & 9.07 & 13.75 & 18.34 & 22.74 \\
\hline$B=-13.07 ; 1979-82$ & 995,483 & 944,723 & 883,887 & 322,810 & 766,357 & 715,740 \\
\hline (loss as \% of original PV) & - • • & 5.10 & 11.21 & 17.35 & 23.01 & 28.10 \\
\hline $\begin{array}{l}\text { loss at } \beta=-13.07 \text { as a } \\
\text { fraction of loss at } \\
B=-4.37\end{array}$ & $\cdot \cdot \cdot$ & 1.154 & 1.236 & 1.262 & 1.255 & 1.236 \\
\hline $\begin{array}{l}\text { difference in loss as } \\
\% \text { of original }\end{array}$ & • • • & 0.68 & 2.14 & 3.60 & 4.67 & 5.36 \\
\hline
\end{tabular}

TABLE 9

AVERAGE TIME TO PAYOFF FOR 10\% MORTGAGES AS A FUNCTION OF MARKET INTEREST RATES

\begin{tabular}{lrrrrrr}
\hline \hline & $10 \%$ & $11 \%$ & $12 \%$ & $13 \%$ & $14 \%$ & $15 \%$ \\
\hline$B=-4.37$ & 5.831 & 6.610 & 7.331 & 7.982 & 8.563 & 9.076 \\
$B=-13.07$ & & & & & & \\
\hline
\end{tabular}


The sensitivity of the average time to repayment to interest rates is shown in Table 9 for ten percent mortgages. The figures indicate that a ten percent mortgage will, on average, prepay in 7.331 years if market rates have gone up to 12 percent and due-on-sale clauses are enforced. If mortgages are assumable, the average time to repayment is 10.337 years. The numbers indicate that interest rate changes alone are sufficient to account for the changing rule of thumb regarding standard lifetime assumptions, but they also indicate how inappropriate any fixed rule of thumb really is.

\section{Conclusion}

We began this research with the feeling that the determinants of prepayment experience had received too little attention. The importance of the matter seemed far too great to uncritically rely on rules of thumb to assess prepayment likelihoods. The first thing we learned in this study was that the data to examine prepayment experience are not readily available. While longitudinal panel surveys do exist for households, similar information regarding mortgages does not seem to be publicly available. We have corrected this situation to an extent by collecting information on 3,938 individual mortgages which were active in 1975 and 1976 and by following them through 1982. Certainly research in the area of mortgage evaluation would be aided by better data. We found the institutions quite willing to provide the data and were limited only by the usual time and money constraints.

Our results indicate that market interest rates are a significant determinant of prepayment probabilities. When due-on-sale clauses were applicable, our information indicates that a ten percent lock-in reduces prepayment probabilities 35 percent. If the clause cannot be enforced, the reduction in 
probability becomes 63 percent. Both of these effects would be eliminated if mortgages had floating interest rates. Our analysis indicates that the rules regarding due-on-sale clauses significantly affect the value of mortgage portfolios, possibly enough in some circumstances to wipe out the net worth of savings and loan institutions. We also find that the average age to prepayment is highly dependent on interest rates. 


\section{Footnotes}

1. The method which resulted in the $\beta=-4.37$ estimate looked only at the mortgages which were at risk in the 1975-78 window. An alternative consistent estimator under the maintained hypothesis of the Proportional Hazards Model would include the experience of these mortgages in the pre-1975 period as well, notwithstanding the fact that the sample is selected so as to include only those which survive to 1975. Reestimating with this alternative, we find $\beta=-2.52$ with a standard error of .46 . The discussion will stick with the original estimate, but this alternative procedure confirms the significant effect of the Wellenkamp decision on mortgage prepayment. 


\section{References}

Dietrich, J. K. "The Economic Effects of Due-on-Sale Clause Invalidation." Working Paper of the Center for the Study of Financial Institutions, School of Business Administration, University of Southern California, May 1982.

Flinn, C. J. and J. Heckman. "Models for the Analysis of Labor Force Dynamics." Advances in Econometrics 1 (1981): 35-95.

- "New Methods for Analyzing Structural Models of Labor Force Dynamics." Journal of Econometrics 18 (1982): 115-68.

Heckman, J. and B. Singer. "Population Heterogeneity in Demographic Models." In K. Land and A. Rogers (eds.), Multidimensional Mathematical

Demography. New York: Academic Press, 1982.

- "The Identification Problem for Econometric Models for Duration Data." Unpublished mimeo, 1982.

Kalbfleisch, J. D. and R. L. Prentice. The Statistical Analysis of Failure Time Data. New York: John Wiley \& Sons, 1980. 